\title{
Kesesuaian Good Handling Practices dan Good Manufacturing Practices Terhadap Mutu Gabah dan Beras di Kabupaten Bogor
}

\author{
Suitability of Good Handling Practices and Good Manufacturing Practices Based on \\ Rice and Milled rice Quality in Bogor Regency
}

\author{
Dwi Zuwarman, Departemen Teknik Mesin dan Biosistem, Institut Pertanian Bogor. \\ Email: dwi_koto76@apps.ipb.ac.id \\ Sutrisno Suro Mardjan, Departemen Teknik Mesin dan Biosistem, Institut Pertanian Bogor. \\ Email: kensutrisno@yahoo.com \\ Rokhani Hasbullah, Departemen Teknik Mesin dan Biosistem, Institut Pertanian Bogor. \\ Email: rokhani@apps.ipb.ac.id
}

\begin{abstract}
Milled rice is one of the most important agricultural commodities for Indonesian people as a staple food. Consumers do not know how to differentiate the good or low quality of rice. Rice Milling Unit (RMU) in Bogor Regency mostly does not have quality standards that comply with the Indonesian National Standard (SNI). The purpose of this study was to1) identify the quality of rice and milled rice produced by RMU in Bogor Regency 2) evaluate the suitability of the application of rice and milled rice handling in RMU to Good Handling Practices (GHP) and Good Manufacturing Practices (GMP). The parameters measured were analysis of rice and milled rice quality. The data obtained in this study, namely descriptive data from the results of interviews and observations, as well as quantitative data from the results of testing the quality of grain and rice. The results showed that four RMU rice samples included in the quality class category below Medium (SNI) and two samples included in Medium III (M-3) quality rice based on SNI 6128: 2015 on the other hand GHP and GMP guidelines were not fully implemented by RMU.
\end{abstract}

Key words: Rice Milling Unit, Good Handling Practices, Good Manufacturing Practices.

\begin{abstract}
Abstrak
Beras merupakan salah satu komoditas pertanian terpenting sebagai makanan pokok masyarakat Indonesia. Konsumen cenderung tidak mengetahui bagaimana cara membedakan beras kualitas yang baik dan kualitas rendah. Beras hasil produksi penggilingan di Kabupaten Bogor belum memiliki gambaran yang menyatakan mutu dan kualitas terhadap Standar Nasional Indonesia (SNI). Tujuan dari penelitian ini adalah 1) untuk mengidentifikasi mutu gabah dan beras yang dihasilkan penggilingan padi di Kabupaten Bogor 2) mengevaluasi kesesuaian penerapan penanganan gabah dan beras di penggilingan terhadap Good Handling Practices/GHP dan Good Manufacturing Practices/GMP. Parameter yang diukur adalah analisis mutu gabah dan beras. Data yang diperoleh dalam penelitian ini, yaitu data deskriptif dari hasil wawancara dan observasi, serta data kuantitatif dari hasil pengujian mutu gabah dan beras. Hasil penelitian menunjukkan bahwa empat sampel beras RMU termasuk kategori kelas mutu dibawah Medium (SNI) dan dua sampel termasuk dalam beras mutu Medium III (M-3) berdasarkan SNI 6128:2015 disisi lain pedoman GHP dan GMP belum sepenuhnya diterapkan oleh penggilingan (RMU).
\end{abstract}

Kata kunci: Rice Milling Unit, Good Handling Practices, Good Manufacturing Practices. 


\section{Pendahuluan}

Beras merupakan salah satu komoditas pertanian yang penting untuk memenuhi kebutuhan masyarakat Indonesia. Menurut Christianto (2013), konsumsi beras di Indonesia pada 2012 mencapai $139.5 \mathrm{~kg}$ per tahun, kondisi ini lebih dari dua kali lipat dari konsumsi rata-rata beras dunia. Konsumsi beras yang tinggi menunjukkan ketergantungan masyarakat Indonesia akan beras. Hal ini menjadikan beras sebagai salah satu makanan pokok bagi masyarakat Indonesia.

Beras yang umumnya dikonsumsi oleh masyarakat Indonesia berasal dari berbagai jenis varietas diantaranya IR 64, Membrano, Ciherang, Inpara 1 dan 2, Inpari 8 dan 13 (Ningsih dan Nafisah 2014). Kecenderungan konsumen dalam memilih beras tidak hanya ditentukan oleh varietas, tetapi juga oleh kualitas: warna beras, persentase beras kepala, aroma dan rasa (Ningsih dan Nafisah 2014). Kualitas beras yang dijual di pasaran mempengaruhi preferensi beras yang dibeli konsumen. Semakin baik kualitas beras, maka konsumen akan semakin menyukainya (Rachmat et al. 2006).

Namun, konsumen cenderung tidak mengetahui bagaimana cara membedakan beras kualitas yang baik dengan kualitas yang rendah (Nurcahyani dan Saptono 2015). Mengingat pentingnya beras dalam pemenuhan kebutuhan pangan, maka perlu untuk melakukan identifikasi dan evaluasi kualitas beras yang dihasilkan di tingkat penggilingan padi khususnya di kabupaten Bogor.

Mutu, varietas dan bentuk gabah akan mempengaruhi hasil beras dan menentukan harganya. Mutu beras ditentukan berdasarkan Standar Nasional Indonesia (SNI 6128:2015). Kesesuaian penanganan pascapanen yang dilakukan di tingkat penggilingan dengan Good Handling Practices (GHP) dan Good Manufacturing Practices (GMP) juga berperan dalam menentukan mutu beras sekaligus keamanan pangannya. Oleh karena itu penelitian ini bertujuan untuk 1) mengidentifikasi mutu gabah dan beras yang dihasilkan penggilingan di Kabupaten Bogor, 2) mengevaluasi kesesuaian penerapan penanganan gabah dan beras di penggilingan terhadap Good Handling Practices (GHP) dan Good Manufacturing Practices (GMP).

\section{Metode}

\section{Bahan dan Alat}

Bahan utama yang digunakan pada penelitian ini adalah gabah kering giling (GKG) dan beras yang diambil dari enam pengilingan padi di Kabupaten Bogor. Gabah yang digunakan berasal dari varietas Ciherang, IR 64 dan pandan wangi, yang dipanen pada musim hujan. Bahan lainnya adalah alkohol $70 \%$ untuk pengujian mutu gabah hampa, plastik kemasan contoh gabah dan beras, kertas label dan bahan wawancara. Peralatan yang digunakan dalam penelitian ini adalah alat pengambil contoh yang terdiri dari sekop gagang pendek, tombak ganda, kayu pembagi, rice whiteness tester Satake C-600 untuk mengukur derajat putih beras dengan menggunakan tabel konvesi nilai derajat sosoh SNI 6128:2015, grain moisture tester untuk mengukur kadar air, cylinder separator dan ayakan diameter $1.8 \mathrm{~mm}$ dan $4.2 \mathrm{~mm}$ untuk memisahkan beras berdasarkan ukuran butiran, timbangan digital untuk bobot contoh gabah/beras, gelas ukur, penyaring untuk mengukur kadar gabah hampa dan pinset untuk pemutuan beras.

\section{Prosedur Penelitian}

Pada enam lokasi penggilingan, dilakukan pengumpulan data dengan metode wawancara, observasi lapangan, dan pengambilan contoh gabah/beras. Wawancara dan observasi lapangan mengacu pada check list dalam Peraturan Menteri Pertanian tentang pedoman GHP/GMP, sedangkan pengambilan contoh gabah/beras dilakukan berdasarkan metode SNI19-0428-1998 tentang petunjuk pengambilan contoh padatan.

Penelitian ini terdiri atas dua tahapan yaitu 1) identifikasi dan penentuan objek penggilingan/ Rice Milling Unit (RMU) dan 2) menentukan mutu gabah, beras dan evaluasi penerapan GHP dan GMP di RMU.

\section{Identifikasi dan penentuan objek penggilingan/ Rice Milling Unit (RMU)}

Penelitian diawali dengan mengidentifikasi dan menentukan responden berdasarkan data kapasitas produksi dengan kriteria penggilingan tebesar dan terkecil dan jam kerja per tahun. Secara umum pengelompokan penilingan padi dibagi dalam tiga skala yaitu: Penggilingan Padi Kecil (PPK) kapasitas produksi <1.5 ton/jam; Penggilingan Padi Sedang (PPS) 1.5-3 ton/ jam; dan Penggilingan Padi Besar (PPB) $>3$ ton/ jam. Pengambilan sampel RMU di Kabupaten Bogor dilakukan berdasarkan pembagian daerah administratif, yakni Bogor Timur, Bogor Tengah dan Bogor Barat. Pembagian sampel tersebut meliputi tiga RMU terkecil, PK.BB (Penggilingan Kecil Bogor Barat); PK.BTE (Penggilingan Kecil Bogor Tengah); PK.BTI (Penggilingan Kecil Bogor Timur) dan tiga RMU terbesar, yaitu PB.BB (Pengilingan Besar Bogor Barat); PB.BTE (Penggilingan Besar Bogor Tengah); PB.BTI (Penggilingan Besar Bogor Timur). Contoh gabah dan beras dibagi menjadi dua kelompok yaitu Penggilingan Padi Kecil (PPK) dan Penggilingan Padi Besar (PPB).

\section{Menentukan mutu gabah dan beras}

Pengujian analisis mutu gabah dan beras dilakukan di Laboratorium Leuwikopo, Laboratorium Teknik Pengolahan Pangan dan Hasil Pertanian 
Tabel 1. Mesin dan teknik penggilingan.

\begin{tabular}{lcccccc}
\hline Komponen & PK.BB & PK.BTE & PK.BTI & PB.BB & PB.BTE & PB.BTI \\
\hline Tipe mesin pengupas kulit & Rubber roll & Rubber roll & Rubber roll & Rubber roll & Rubber roll & Rubber roll \\
gabah Merk & ichi & ichi & ichi & ichi & ichi & yanmar \\
Tahun mesin & 1997 & 2004 & 2002 & 1998 & 2009 & 1998 \\
Jenis, Tipe mesin & Friksi lchi & friksi ichi & friksi ichi & friksi ichi & friksi ichi & Friksi ichi \\
penyosoh, Merk & & & N 70 & & & N 120 \\
Tahun mesin & 1994 & 2000 & 1998 & 1998 & 2009 & 1995 \\
Konfigurasi penggilingan & $2 \mathrm{H}-2 \mathrm{P}$ & $2 \mathrm{H}-\mathrm{P}$ & $\mathrm{H}-\mathrm{S}-2 \mathrm{P}$ & $2 \mathrm{H}-\mathrm{P}$ & $2 \mathrm{H}-\mathrm{P}$ & $2 \mathrm{H}-\mathrm{S}-2 \mathrm{P}$ \\
Beras kepala & $74.3 \%$ & $76.7 \%$ & $85.4 \%$ & $77.3 \%$ & $73 \%$ & $79.6 \%$ \\
\hline
\end{tabular}

Keterangan: $\mathrm{H}=$ husking (pengupasan kulit gabah); $\mathrm{S}=$ Separation (pengayakan); $\mathrm{P}=$ Polishing (penyosohan); $\mathrm{PK}$.BB (Pengilingan Kecil Bogor Barat); PK.BTE (Penggilingan Kecil Bogor Tengah); PK.BTI (Penggilingan Kecil Bogor Timur); PB.BB (Pengilingan Besar Bogor Barat); PB.BTE (Penggilingan Besar Bogor Tengah); PB.BTI (Penggilingan Besar Bogor Timur)

Departemen Teknik Mesin dan Biosistem Fakultas Teknologi Pertanian IPB Dramaga. Pengujian mutu yang ditetapkan oleh SNI 01-0224-1987 yaitu kadar air, persentase gabah hampa, butir rusak/kuning, butir mengapur/hijau, butir merah, benda asing, dan gabah varietas lain (BSNI 1987). Sedangkan pengujian mutu beras dilakukan berdasarkan kriteria mutu dalam SNI 6128:2015 yaitu meliputi derajat sosoh, kadar air, persentase beras kepala, beras patah, butir menir, butir merah, butir kuning/ rusak, butir mengapur, benda asing, dan persentase butir gabah (BSN 2015).

Analisis laboratorium dilakukan untuk menguji parameter mutu gabah dan beras. Analisis mutu gabah yang dilakukan meliputi parameter mutu kadar air dengan metode gravimetri berdasarkan AOAC (1990), gabah hampa, butir rusak dan kuning, butir mengapur dan gabah muda, gabah merah, benda asing, dan gabah varietas lain berdasarkan metode SNI 01-0224-1987, sedangkan analisis mutu beras yang dilakukan meliputi parameter mutu kadar air dengan metode gravimetri berdasarkan AOAC (1990), beras kepala, butir patah, butir menir, butir kuning/rusak, butir kapur, benda asing, butir gabah, dan Pengukuran derajat sosoh dilakukan secara kuantitatif menggunakan milling meter/whiteness meter dengan metode konversi. Sejumlah 15 sampai 20 gram contoh beras diukur nilai derajat putihnya menggunakan milling meter/whiteness meter, kemudian dikonversi ke nilai derajat sosoh menggunakan tabel konversi berdasarkan SNI 6128:2015(BSN 2015). Pengujian mutu gabah dan beras dilakukan dengan menyiapkan sampel sebanyak 100 gram yang telah dipisahkan dari gabah hampa dan dikupas dengan mini husker. Dihitung secara manual untuk dianalisa mutu berdasarkan SNI sebanyak 3 ulangan.

Data hasil analisis laboratorium gabah dan beras dibandingkan dengan standar untuk menentukan kelas mutunya, sedangkan hasil wawancara dan observasi lapang dinilai kesesuaiannya terhadap pedoman GHP/GMP kemudian dihitung tingkat kesesuaiannya menggunakan rumus :

$T K(\%)=\frac{A}{B} \times 100 \%$

Keterangan :

$T K=$ tingkat kesesuaian (\%); $A=$ jumlah jawaban

sesuai; $B$ : jumlah parameter penilaian GHP/GMP.

\section{Analisis Data}

Penyajian data dilakukan berupa tabulasi, selanjutnya dilakukan analisis menggunakan ANOVA (Analysis of variance) dengan tingkat kepercayaan $95 \%$. Apabila data yang di uji berbeda nyata, maka dilakukan uji lanjut menggunakan DMRT (Duncan Multiple Range Test).

\section{Hasil dan Pembahasan}

\section{Identifikasi dan penentuan objek penggilingan (RMU)}

Hasil evaluasi RMU Kabupaten Bogor menunjukkan bahwa empat sampel RMU menggunakan konfigurasi mesin husker-polisher dan dua sampel menggunakan konfigurasi husker-separator-polisher dapat dilihat pada Tabel 1. Konfigurasi husker-polisher menghasilkan beras kepala yang lebih rendah dibandingkan konfigurasi husker-separator-polisher. Hal ini sejalan dengan Hassan (2014) yang menyatakan bahwa penggunaan separator dapat mengurangi resiko beras patah. Dari hasil analisis umur mesin yang digunakan RMU Kabupaten Bogor dapat diketahui bahwa umur mesin tidak linear terhadap hasil persentase beras kepala. Pada Tabel 1 dapat dilihat bahwa RMU Kabupaten Bogor PK.BTI menggunakan mesin rubber roll husker tahun 2002 dan polishertipe friksitahun 1998 dengan konfigurasi husker-separator-2polisher sehingga menghasilkan beras kepala tertinggi dengan persentase $85.4 \%$ dibandingkan RMU PB.BTE yang menggunakan mesin penggilingan husker dan polisher tahun 2009 
Tabel 2. Kelas mutu gabah berdasarkan SNI 01-0224-1987.

\begin{tabular}{lccrrr}
\hline Komponen mutu (\%) & \multicolumn{2}{c}{ Mutu gabah } & \multicolumn{3}{c}{ Kelas mutu SNI } \\
\cline { 2 - 6 } & PPK & PPB & I & II & III \\
\hline Kadar air (maks) & $14.0 \mathrm{a}$ & $12.7 \mathrm{a}$ & 14 & 14 & 14 \\
Butir hampa (maks) & $11.0 \mathrm{a}$ & $6.6 \mathrm{a}$ & 1 & 2 & 3 \\
Butir rusak/kuning (maks) & $2.4 \mathrm{a}$ & $1.2 \mathrm{a}$ & 2 & 5 & 7 \\
Butir mengapur/ hijau (maks) & $5.0 \mathrm{a}$ & $3.0 \mathrm{a}$ & 1 & 5 & 10 \\
Butir merah (maks) & $0.2 \mathrm{a}$ & $0.1 \mathrm{a}$ & 1 & 2 & 4 \\
Benda asing (maks) & $0.0 \mathrm{a}$ & $0.0 \mathrm{a}$ & 0 & 2 & 4 \\
Varietas lain (maks) & $0.0 \mathrm{a}$ & $0.0 \mathrm{a}$ & 2 & 5 & 10 \\
\hline Kelas mutu gabah & $*$ & $*$ & & &
\end{tabular}

Keterangan : PPK (Pengilingan Padi Kecil); PPB (Pengilingan Padi Besar); * (Tidak memenuhi SNI); PPK (Pengilingan Padi Kecil); PPB (Pengilingan Padi Besar). Angka diikuti huruf yang sama pada baris tidak berbeda nyata berdasarkan uji Duncan pada tingkat kepercayaan $95 \%$.

Tabel 3. Kelas mutu beras kabupaten Bogor berdasarkan SNI 6128:2015.

\begin{tabular}{lccrrrr}
\hline Komponen Mutu (\%) & \multicolumn{3}{c}{ Mutu Beras Kabupaten Bogor } & \multicolumn{3}{c}{ Kriteria Mutu } \\
\cline { 2 - 7 } & PPK & PPB & P & M-1 & M-2 & M-3 \\
\hline Kadar air (maks) & $15.5 a$ & $14.1 a$ & 14 & 14 & 14 & 15 \\
Beras kepala (min) & $78.8 a$ & $76.6 a$ & 95 & 78 & 73 & 60 \\
Butir patah (maks) & $17.1 a$ & $19.1 a$ & 5 & 20 & 25 & 35 \\
Butir menir (maks) & $3.3 a$ & $3.7 a$ & 0 & 2 & 2 & 5 \\
Butir merah (maks) & $0.1 a$ & $0.0 a$ & 0 & 2 & 3 & 3 \\
Butir kuning/rusak (maks) & $0.4 a$ & $0.3 a$ & 0 & 2 & 3 & 5 \\
Butir kapur (maks) & $0.2 a$ & $0.2 a$ & 0 & 2 & 3 & 5 \\
Benda asing (maks) & $0.0 a$ & $0.0 a$ & 0 & 0 & 0 & 0.2 \\
Butir gabah (maks) & $0.0 a$ & $0.0 a$ & 0 & 1 & 1 & 3 \\
Derajat sosoh (min) & $79.3 a$ & $83.3 a$ & 100 & 95 & 90 & 80 \\
\hline Kelas mutu beras & $*$ & M-3 & & & & \\
\hline
\end{tabular}

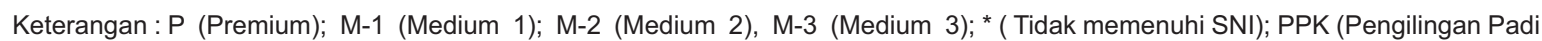
Kecil); PPB (Pengilingan Padi Besar). Angka diikuti huruf yang sama pada baris tidak berbeda nyata berdasarkan uji Duncan pada tingkat kepercayaan $95 \%$.

dengan konfigurasi 2husker-polisher menghasilkan persentase beras kepala terendah yakni sebesar $73 \%$.

\section{Menentukan Mutu Gabah dan Beras.}

\section{Mutu Gabah}

Berdasarkan hasil analisis ragam mutu gabah (Tabel 2) dapat diketahui bahwa semua komponen mutu di kedua RMU yaitu: PPK dan PPB tidak berbeda nyata. Semua komponen mutu di kedua RMU memenuhi persyaratan maksimum kelas mutu SNI, terkecuali pada komponen mutu butir hampa. Persentase butir hampa pada kedua RMU mencapai $6.6 \%$ sampai dengan $11 \%$, sedangkan persentase maksimum berdasarkan SNI adalah $3 \%$. Hal ini menyebabkan mutu gabah pada kedua RMU tidak memenuhi persyaratan mutu SNI baik kelas I, II atau III.

\section{Mutu Beras}

Hasil analisis ragam mutu beras (Tabel 3) juga menunjukkan bahwa semua komponen mutu di kedua RMU yaitu: PPK dan PPB tidak berbeda nyata. RMU PPK tidak memenuhi kriteria mutu SNI karena persentase kadar air yang melebihi batas maksimal yaitu 15\%. Sementara itu RMU PPB tergolong ke dalam kriteria mutu M-3.

\section{Kadar Air}

Kadar air beras (Gambar 1) pada RMU: PPK dan PPB adalah $14.1 \%$ dan $15.5 \%$. Sementara itu kadar air gabah $14 \%$ dan 12,7\%. Kadar air beras pada RMU PPB masih memenuhi batas maksimal kadar air berdasarkan SNI yaitu 15\%, sedangkan kadar air beras pada RMU PPK tidak memenuhi batas ini. Menurut Sarastuti (2018), tingginya kadar air beras erat kaitannya dengan tingginya kadar air Gabah Kering Giling (GKG). Hasil analisis juga menunjukkan bahwa kadar air gabah pada RMU 
PPK lebih tinggi daripada nilai kadar air gabah pada RMU PPB.

Hasil survei menunjukkan bahwa dari enam penggilingan, hanya satu penggilingan yang menggunakan alat ukur kadar air. Pemeriksaan kadar air oleh RMU Kabupaten Bogor secara umum masih dilakukan dengan cara manual yaitu melalui pengamatan visual serta pengamatan fisik dengan cara menggigit gabah. Kadar air gabah yang telah memenuhi persyaratan ditandai dengan adanya bunyi patahan pada saat gabah digigit. Proses penjemuran gabah di tingkat RMU PPK dan PPB dihentikan sebelum kadar air $14 \%$. Kadar air gabah PPK dan PPB memenuhi mutu kadar air GKG dalam SNI 01-0224-1987 yaitu maksimal 14\%.

\section{Butir Kapur}

Hasil analisis Gambar 2 butir kapur gabah menunjukan RMU PPK lebih banyak mengandung butir kapur yaitu $5 \%$, lebih tinggi dari RMU PPB dengan persentase $3 \%$. Sementara itu butir kapur beras baik pada RMU PPK dan PPB memiliki persentase yang sama yaitu $0.2 \%$. Dari hasil persentase butir kapur gabah dan beras, kedua RMU memenuhi persyaratan SNI yaitu maksimal $5 \%$. Butir mengapur dan gabah muda dengan persentase tinggi disebabkan oleh faktor pemanenan gabah yang terlalu cepat, faktor lingkungan dan faktor budidaya. Menurut Anhar et al. (2012), faktor lingkungan seperti infeksi penyakit dan kekeringan pada saat pengisian gabah saat pematangan menyebabkan butir kapur pada beras. Pemanenan gabah yang terlalu awal juga menghasilkan butir mengapur dan hijau yang tinggi (Sulardjo 2014).

\section{Beras Kepala, Butir Patah dan Butir Menir}

RMU PPK memiliki nilai persentase 78.8\% untuk beras kepala, lebih tinggi dari RMU PPB yaitu $76.6 \%$. Nilai persentase butir patah $17.1 \%$ dan butir menir 3.3\% pada RMU PPK, lebih rendah dibandingkan dengan RMU PBB yaitu 19.1\% butir patah dan $3.7 \%$ butir menir. Hal ini menunjukan beras kepala, butir patah dan butih menir pada RMU PPK lebih tinggi dari RMU PPB (Gambar 3).

Persentase beras kepala dipengaruhi oleh tingkat kadar air gabah yang digunakan. Berdasarkan Tabel 1, pengeringan gabah hasil panen di RMU kabupaten Bogor dilakukan hingga mencapai kadai air GKG $12.7 \%-14 \%$. Proses ini menghasilkan beras kepala yang berkualitas baik sehingga memenuhi persyaratan SNI Mutu I. Indrasari et al. (2006) menyatakan bahwa kadar air GKG yang optimum untuk menghasilkan beras kepala yang baik berasa pada kisaran $14 \%-15 \%$.

\section{Benda Asing dan Butir Kuning/Rusak}

Berdasarkan Tabel 2 dan 3, hasil analisis mutu gabah dan beras di RMU kabupaten Bogor tidak menghasilkan benda asing, sehinga memenuhi persyaratan mutu Premium (P) pada SNI. Butir kuning atau rusak pada beras mencapai adalah $0.3 \%-0.4 \%$ sehingga memenuhi persyaratan mutu Medium I (M-1). Hal ini membuat mutu gabah di RMU kabupaten Bogor secara umum memiliki kemurnian yang baik. Sesuai dengan Hasbullah dan Dewi 2012 bahwa parameter mutu benda asing dan butir rusak atau kuning menunjukkan kemurnian gabah.

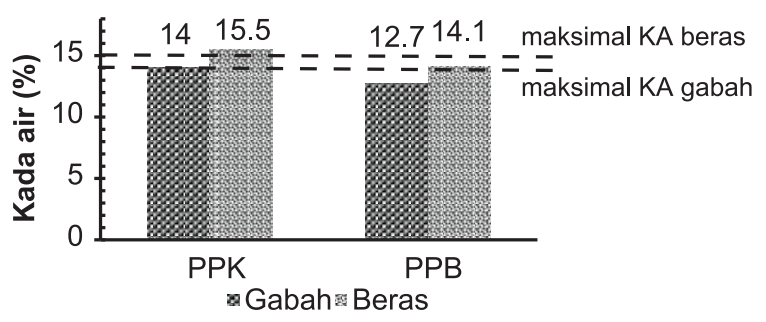

Gambar 1. Kadar air gabah dan beras.

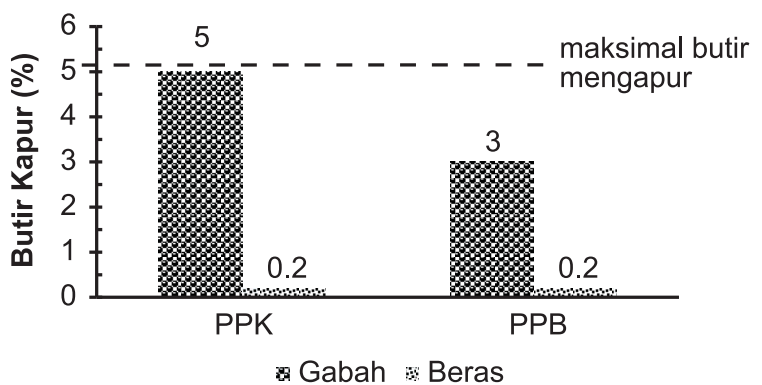

Gambar 2. Butir mengapur dan gabah muda.

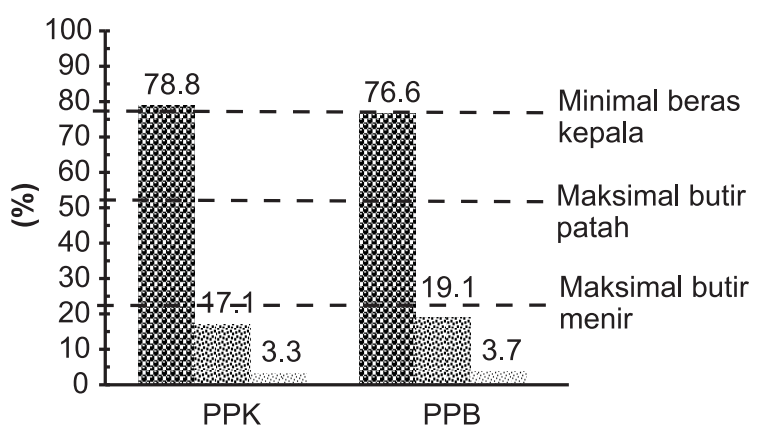

- Beras kepala $\approx$ butir patah : butir menir

Gambar 3. Beras kepala, butir patah dan butir menir.

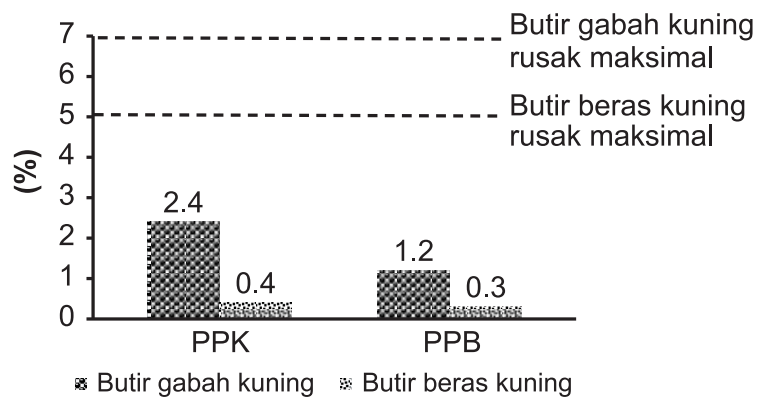

Gambar 4. Butir kuning/rusak. 


\section{Butir Gabah}

Berdasarkan hasil analisis pada Tabel 1, beras di RMU Kabupaten Bogor tidak mengandung butir gabah. Konfigurasi pada mesin husker dan teknik pengupasan diduga mempengaruhi jumlah butir gabah pada beras. Berdasarkan hasil survei, $66.6 \%$ responden menggunakan konfigurasi huskerpolisher dan 33.4\% menggunakan konfigurasi husker-separator-polisher. Diketahui bahwa RMU yang menggunakan konfigurasi husker-separatorpolisher melakukan pengupasan kulit gabah dua lintasan dan satu lintasan kemudian gabah diumpankan ke mesin pengayak untuk memisahkan gabah dengan beras pecah kulit (BPK). BPK diumpankan kemesin penyosoh, sedangkan gabah yan belum terkupas diumpan kembali ke mesin husker.

\section{Butir Merah}

Beras di RMU kabupaten Bogor mengandung butir merah sebanyak $0-0.1 \%$ sehingga memenuhi persyaratan mutu Medium I (M-1). Hal ini sejalan dengan hasil analisis persentase gabah merah di tingkat RMU $0.1-0.2 \%$ sehingga memenuhi persyaratan mutu Mutu I. (Gambar 5).

\section{Derajat Sosoh}

Beras RMU PPK Kabupaten Bogor memiliki derajat sosoh $79.3 \%$, tidak memenuhi persyaratan mutu SNI sementara itu derajat sosoh RMU PPB yaitu $83 \%$ memenuhi persyaratan mutu Medium III (M-3) SNI. Jika hasil ini dibandingkan dengan derajat sosoh kelas mutu beras berdasarkan standar mutu Peraturan Menteri Pertanian Nomor: 31/Permentan/PP.130/8/2017 (derajat sosoh minimal 95\%), maka RMU Kabupaten Bogor tidak memenuhi persyaratan mutu.

Dari hasil survei, RMU Kabupaten Bogor menggunakan konfigurasi mesin rubber roll huskerpolisher tipe friksi. Penggunaan polisher tipe ini menyebabkan derajat sosoh yang didapatkan lebih rendah. Hal ini sejalan dengan Indrasari et al. (2006) bahwa penyosohan tipe friksi menghasilkan beras dengan derajat putih rendah disebabkan oleh panas yang dihasilkan dari putaran silinder besi baja dalam alat dan mengakibatkan warna beras menjadi biru kehitaman.

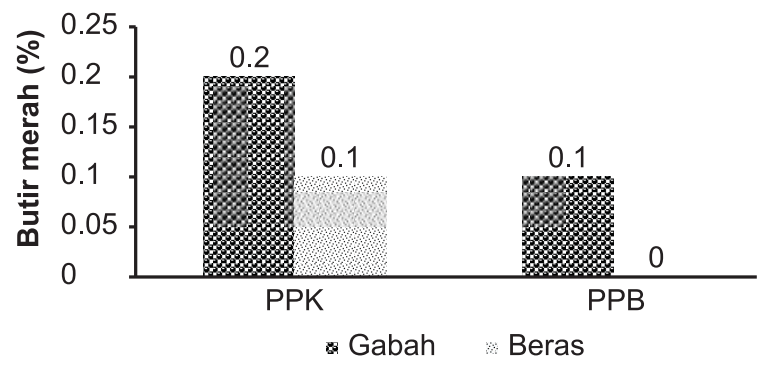

Gambar 5. Butir gabah merah dan butir merah.

\section{Penerapan GHP dan GMP di RMU}

\section{Penerapan Good Handling Practice (GHP)}

Penjemuran gabah yang dilakukan RMU Kabupaten Bogor sudah mengikuti pedoman GHP. Pengeringan dilakukan dengan hati-hati pada alas bersih berupa terpal atau lantai jemur yang sudah disemen untuk penjemuran gabah kering panen (GKP). Keenam RMU tidak melakukan grading gabah kering giling sesuai standar mutu dari SNI. Kemasan gabah di RMU Kabupaten Bogor mengunakan karung plastik. Dari segi kemasan, hal ini sesuai dengan GHP RMU telah memenuhi persyaratan kemasan yang masih dapat melindungi hasil panen dari kerusakan dalam pengangkutan atau penyimpanan.

\section{Penerapan Good Manufacturing Practice (GMP)}

Berdasarkan hasil survei, mesin dan peralatan penggilingan di tingkat RMU Kabupaten Bogor 100\% telah sesuai dengan tujuan proses penggilingan. Hasil analisis penerapan GMP tingkat kesesuaian GMP adalah $58.97 \%$ pada penggilingan kecil dan $61.53 \%$ pada penggilingan besar, perbedaan yang tidak terlalu besar terletak pada aspek fasilitas bangunan.

$50 \%$ RMU memiliki bangunan dengan lantai padat, keras, kedap air dan tahan air/garam/asam/ basa, 83.3\% RMU memiliki atap tahan lama, tahan air, tidak bocor, terbuat dari bahan yang tidak mengelupas, minimum 3 meter diatas lantai; ventilasi cukup untuk sirkulasi udara yang baik dan menjamin sirkulasi udara, 100\% RMU memiliki dinding kedap air; tetapi hanya $50 \%$ yang memiliki lantai rata, halus, tidak licin, mudah dibersihkan, $100 \%$ RMU memiliki langit yang berlubang atau retak, tahan lama, mudah dibersihkan, minimum 2.5 meter di atas lantai, permukaan halus, rata, berwarna terang, tidak mudah mengelupas, tidak bocor, $16.7 \%$ RMU memiliki dinding halus, rata, berwarna terang, tidak mudah terkelupas, tahan air/garam/asam/basa, mudah dibersihkan, tahan lama dan 100\% RMU tidak memiliki lubang-lubang ventilasi yang dapat mencegah masuknya hama, debu, kotoran dan mudah di bersihkan. Hal ini menyebabkan ruangan proses menjadi lembab sehingga memudahkan hama dan serangga untuk mencemari produk beras yang akan disimpan.

\section{Simpulan}

Mutu beras penggilingan padi kecil (PPK) tidak memenuhi persyaratan mutu SNI, sedangkan penggilingan padi besar (PPB) memenuhi persyaratan SNI Medium III (M-3). Berdasarkan SNI 6128:2015, beras tidak memenuhi persyaratan SNI karena memiliki kadar air tinggi, butir menir tinggi dan derajat sosoh lebih rendah dari persyaratan.

Tingkat kesesuaian GHP $41.66 \%$ untuk 
penggilingan padi kecil dan $44.44 \%$ untuk penggilingan padi besar, sedangkan tingkat kesesuaian GMP adalah $58.97 \%$ penggilingan padi kecil dan $61.53 \%$ untuk penggilingan padi besar. Maka secara keseluruhan pedoman GHP dan GMP belum sepenuhnya diterapkan oleh RMU. Penyebab ketidaksesuaian ini berasal dari aspek fasilitas meliputi kondisi bangunan gudang penyimpanan.

\section{Daftar Pustaka}

Anhar, A., I.L.E. Putri, S.B. Etika. 2012 Stabilitas mutu beras kelas satu terhadap lokasi dan musim tanam di Sumatera Barat [Laporan penelitian hibah bersaing]. Padang (ID): Universitas Negeri Padang.

AOAC. 1990. Moisture Content Determination. Official Methods of Analysis of the Association of Official Analytical Chemist.Association of Official Analytical Chemist. Washingthon. USA.

Badan Standardisasi Nasional Indonesia. 1987. Standar Mutu Gabah. SNI 01-0224-1987. Jakarta

Badan Standardisasi Nasional. 2015. Standar Nasional Indonesia Beras. SNI 6128 : 2015. Jakarta

Christianto, E. 2013. Faktor yang Mempengaruhi Volume Impor Beras di Indonesia. Jurnal JIBEKA. 7(2):38-43.
Hasbullah, R., A.R. Dewi. 2012. Teknik Penanganan Pascapanen Padi untuk Menekan Susut dan Meningkatkan Rendemen Giling. Artikel Pangan. 21 (1): 17-28.

Rachmat, R., R. Thahir, M. Gummert. 2006. The empirical relationship between price and quality of rice at market level in West Java. Indonesian Journal of Agricultural Science 7(1):27-33.

Ningsih, R.D. dan K. Nafisah. 2014. Preferensi Konsumen Kalimantan Selatan Terhadap Beras dan Rasa Nasi Varietas Unggul. Prosiding Seminar Nasional "Inovasi Teknologi Pertanian Spesifik Lokasi”, 2014 agus 6-7. Banjarbari (ID). hlm 265.

Sarastuti, U. Ahmad, Sutrisno. 2018. Analisis Mutu Beras dan Penerapan Sistem Jaminan Mutu dalam Kegiatan Pengembangan Usaha Pangan Masyarakat. J. Penelit Paspapanen Pertan. 15(2): 63-72

Indrasari, S.D., Jumali, A.A. Darjat 2006. Kualitas Beras Giling dan Nilai Duga Derajat Sosoh Gabah Beberapa Varietas Padi. Penelitian Pertanian Tanaman Pangan. 25(3): 194-199.

Sulardjo. 2014. Penanganan Pascapanen Padi. Magistra. 88.44-58.

Sutrisno dan D.R. Achmad. 2008. Pengaruh ukuran dan bentuk gabah terhadap rendemen dan mutu beras giling. Seminar Nasional Padi: 1505-1516. 
Halaman ini sengaja dikosongkan 